\title{
PROPOSTA DE IMPLEMENTAÇÃO DA FERRAMENTA 5W2H NA GESTÃO DOS PROCESSOS DE ATENDIMENTO AO CLIENTE: ESTUDO DE CASO DA LOJA CLARO DO AMAZONAS SHOPPING
}

\section{ARTIGO ORIGINAL}

ALFAIA, Samuel Pinheiro ${ }^{1}$, SOUZA, Josiane Santana de ${ }^{2}$, ALMEIDA, Victor da Silva ${ }^{3}$, ROBERTO, José Carlos Alves ${ }^{4}$

ALFAIA, Samuel Pinheiro. Et al. Proposta de implementação da ferramenta 5w2h na gestão dos processos de atendimento ao cliente: estudo de caso da loja claro do Amazonas shopping. Revista Científica Multidisciplinar Núcleo do Conhecimento. Ano 06, Ed. 05, Vol. 04, pp. 41-61. Maio de 2021. ISSN: 2448-0959, Link de acesso: https://www.nucleodoconhecimento.com.br/administracao/ferramenta-5w2h, DOI: 10.32749/nucleodoconhecimento.com.br/administracao/ferramenta-5w2h

\section{RESUMO}

Este artigo tem a finalidade de apresentar os resultados da análise realizada por meio de diagnóstico organizacional executado na loja Claro, situada no Amazonas Shopping, bem como expor proposta de implementação por meio de dados fundamentados, visando a solução dos problemas obtidos através da análise.

${ }^{1}$ Graduando do curso de Administração.

${ }^{2}$ Graduanda do curso de Administração.

3 Coorientador. Mestre em Engenharia de Processos. Pós-Graduando em Neuropsicopedagogia Institucional. Especialista em Gestão Estratégica de RH. Graduado em Administração e Pedagogia.

${ }^{4}$ Orientador. Mestrado profissional em Engenharia de produção. Especialização em Gestão em Logística empresarial. Graduação em Administração com Ênfase em Marketing.

RC: 84591

Disponível em: https://www.nucleodoconhecimento.com.br/administracao/ferramenta-5w2h 
Podemos destacar a utilização da ferramenta da qualidade $5 \mathrm{~W} 2 \mathrm{H}$ no planejamento de estratégia com o intuito de potencializar os serviços de vendas e soluções de problemas de clientes executados por esta empresa de telefonia. A execução deste artigo tomou como base uma pesquisa bibliográfica de abordagem qualitativa. Mediante análise dos dados desta pesquisa, o grupo obteve uma visão com mais do que se faz necessário para melhoria nos processos de serviços prestados no estabelecimento proposto no estudo.

Palavras-chave: Implementação, estratégia, serviços, estabelecimento.

\section{INTRODUÇÃO}

A proposta desta pesquisa deu-se por uma pesquisa de campo realizada na loja do Amazonas shopping onde foi constatado uma falha nos processos funcionais da loja devido à demora no atendimento e ocasionava perda de clientes que aguardavam com intuito de adquirir algum produto ou serviço da operadora, isso impactava diretamente nos resultados da loja. Foi feita a implementação da ferramenta da qualidade $5 \mathrm{~W} 2 \mathrm{H}$ a fim de executar um plano de ação a fim de maximizar as vendas e trazer melhoria aos processos. De acordo com os dados encontrados foi possível observar uma falha no atendimento com relação ao excesso de fluxos documentais, tempo de atendimento e na filtragem dos serviços prestados na loja.

Covey (2019, p. 42) diz que "se queremos mudar efetivamente nosso modo de ser é preciso primeiro mudar a nossa percepção"

Foi realizada uma pesquisa teórica que coloca assuntos como: foco em educação corporativa, administração de tempo, tipos de serviços de atendimento, impactos no atendimento, agilidade no atendimento e endomarketing, a fim de dar uma fundamentação teórica para a pesquisa.

Este artigo refere se a área de processos nas áreas de atendimento ao público não somente a área telefonia, mas de atendimento em geral. A todos os estabelecimentos

RC: 84591

Disponível em: https://www.nucleodoconhecimento.com.br/administracao/ferramenta-5w2h 
que sofrem com uma superlotação ou tem um fluxo intenso de clientes para que possa ser relevante na procura por mudanças.

Como uma política de treinamento voltada ao incremento do nível de serviço pode proporcionar a redução do tempo de atendimento aos clientes? Proposta de implementação da ferramenta $5 \mathrm{~W} 2 \mathrm{H}$ na gestão dos processos de atendimento ao cliente: Estudo de caso na Loja Claro do Amazonas Shopping. A hipótese que tratamos será referente a um redesenho de processos, no caso um novo fluxograma e treinamentos e um novo tipo de filtragem baseando-se na ferramenta da qualidade $5 \mathrm{~W} 2 \mathrm{H}$.

Objetivo geral: desenvolver um plano de ação para melhorar o atendimento ao cliente de uma operadora telefônica.

Objetivos específicos: Identificar como a agilidade no atendimento pode se tornar um diferencial competitivo na captação de clientes; analisar as causas do problema na demora de atendimento da loja; aplicar plano de ação para treinamento e capacitação de funcionários.

\section{FUNDAMENTAÇÃO TEÓRICA}

Trata-se da revisão de conteúdos textuais de revistas, livros, artigos, sites ou demais conteúdos pertinentes à revisão bibliográfica com o intuito de obter embasamento aos trabalhos de caráter científico. É por meio da fundamentação teórica que se pode legitimar todo conhecimento produzido no trabalho, garantindo uma boa base aos conceitos e processos para pesquisa.

Conforme Libório e Terra (2015, p. 40) "Refere-se a parte do desenvolvimento propriamente dito, em que o autor expõe as afirmações de outros teóricos e pesquisas relacionadas ao tema, discutindo-as conforme as perspectivas do seu próprio trabalho".

RC: 84591

Disponível em: https://www.nucleodoconhecimento.com.br/administracao/ferramenta-5w2h 


\subsection{TREINAMENTO}

O treinamento dos colaboradores constitui parte fundamental para manutenção e aprimoramento nos processos de bens e serviços oferecidos. É por meio dele que se obtém funcionários mais qualificados e capacitados, conduzindo a empresa para os seus objetivos e metas de maneira eficaz.

De acordo com Souza e Gonçalves (2012, p. 4) "Para manter-se competitiva no mercado atual as empresas precisam cultivar seus principais ativos, as pessoas, desenvolvendo suas competências e treinando-as para terem uma maior eficácia na execução de suas atividades".

Existem diferentes tipos de treinamento na empresa. Os mais tradicionais são executados de forma presencial com orientador, os benefícios deste tipo de treinamento são as interações sociais e com isso fortalece as relações entre os colaboradores e o instrutor. Treinamentos como: Orientação (geralmente dado à novos funcionários com intuito de informar sobre políticas da empresa, sua missão, visão e valores), onboarding (também ministrado aos novos funcionários, tendo como orientadores os seus líderes departamentais, seu objetivo é capacitá-los para exercerem suas funções da melhor forma possível), desenvolvimento de habilidades técnicas (este treinamento geralmente é ministrado quando ocorre uma mudança no processo, seja por uma nova máquina ou mesmo para melhoria de método de serviço), obrigatórios (ministrado pela segurança do trabalho, bombeiros e/ou demais setores competentes para atuar neste treinamento aos colaboradores) e mentoria (com o objetivo de motivar os funcionários e consequentemente aumentar o desempenho produtivo da empresa).

\subsubsection{FOCO EM EDUCAÇÃO CORPORATIVA}

Trata-se do foco das organizações em busca do contínuo aperfeiçoamento das pessoas. Tal foco tem sua abrangência além de funcionários, alcançando também os envolvidos em seus processos em um todo, como fornecedores, clientes e a RC: 84591

Disponível em: https://www.nucleodoconhecimento.com.br/administracao/ferramenta-5w2h 
sociedade, buscando criar certo valor para a contribuição da produtividade, alcançando metas e desenvolvimento saudável da empresa.

Para aprender, deve-se primeiro desaprender, porém, isso é muito complicado, pois parte da capacidade de "renúncia" não está incorporada ao sistema de valores, da sociedade, em muitas ocasiões. (OSHIRO, 2011, p. 13).

\subsubsection{ADMINISTRAÇÃO DE TEMPO}

A desorganização impossibilita que se concluam atividades dentro do prazo. É desempenhando um bom gerenciamento de tempo que se pode obter bons resultados à medida que surgem novas atividades a serem realizadas no decorrer do dia. Funcionários que administram bem seu tempo garantem o sucesso produtivo da organização, é através desta que o desenvolvimento do trabalho pode a cada dia atingir suas devidas metas, porém, este desempenho pode melhorar muito mais ao integrar-se em uma interação conjunta entre colaboradores, fornecedores e demais envolvidos nos processos produtivos.

Segundo Martins e Bonfim (2017, p. 12) "O gerenciamento do tempo é uma das preocupações mais importantes para a direção da empresa, na qual, frequentemente, visa encontrar a quantidade de produtos que se consegue produzir em determinado espaço de tempo".

Medidas como definir prioridade de afazeres, encarregar tarefas, estipular horários para realização de cada atividade, fazer o que puder para evitar procrastinação garantem um melhor desempenho na execução de atividades.

\subsubsection{TIPOS DE SERVIÇO DE ATENDIMENTO AO CLIENTE}

Atualmente, com a tecnologia a nosso alcance, dispomos de novas ferramentas para atendimento ao cliente, buscando sempre proporcionar mais comodidade aos mesmos. Ferramentas como mídia sociais, chats, mensagens de texto e vídeo

RC: 84591

Disponível em: https://www.nucleodoconhecimento.com.br/administracao/ferramenta-5w2h 
conferências geralmente encontradas nos sites da empresa vêm ganhando cada vez mais espaço. Não podemos deixar de citar os tipos de serviços já presentes antes mesmo da tecnologia atual e que ainda tem seu papel fundamental para a comunicação com o cliente, como o atendimento por meio telefônico e no próprio ponto de venda.

Para Medeiros, Cruz e Antoni (2013, p. 11) "Trocas relacionais estreitam a ligação entre empresas e clientes, estimulando a preferência e a lealdade e desenvolvendo barreiras de saída, ou migração do cliente para a concorrência".

\subsection{REUNIÕES DE ACOMPANHAMENTO}

As reuniões de acompanhamento servem para realizar o controle na condução de processos e tarefas que estão em andamento, bem como o acompanhamento de performance dos funcionários da organização, de modo geral.

A reunião de equipe tem como proposta reunir os trabalhadores, com vistas ao planejamento conjunto, à discussão e decisão de casos e situações, proporcionando que os envolvidos tenham maior clareza sobre os papéis que desempenham no processo de trabalho (SANTOS et al., 2017, p. 607).

\subsubsection{IMPACTOS NO ATENDIMENTO}

Colaboradores que se mantêm atualizados sobre o que acontece em seu local de trabalho durante o expediente e buscam a melhoria em etapas dificultosas garantem o aperfeiçoamento e melhoria contínua em seus processos.

É por meio de reuniões de acompanhamento que os colaboradores podem trocar informações sobre fatos ocorridos no dia, desta forma um colaborador pode expor algo que outro colaborador não notou e ambos podem trabalhar em conjunto para a melhoria ou mesmo mudança naquilo que foi exposto.

RC: 84591

Disponível em: https://www.nucleodoconhecimento.com.br/administracao/ferramenta-5w2h 
De acordo com Medeiros, Cruz e Antoni (2013, p. 19) "Falhas no atendimento são inevitáveis e se não forem resolvidas pontualmente, não apenas colocam em jogo a imagem da empresa, mas afetam o caixa de forma imediata".

\subsection{FLUXO DE DOCUMENTOS}

As documentações são de grande ajuda para questões de caráter burocrático, são através delas que se registram compras, cadastros, propostas, termos, contratos, dentre outras informações pertinentes à assuntos de interesse tanto do cliente quanto da empresa.

O fluxo documental em uma loja serve para tramitação de dados com o propósito de gerar informações completas a respeito de determinada ação, seja para uma compra e venda, um cadastro do cliente para obtenção de cartão da loja, as informações do vendedor que está efetuando determinada venda.

Para Teixeira e Aganette (2018, p. 436) "Todas as organizações necessitam de algum tipo de informação ou conhecimento para dar continuidade aos processos, sejam essas simples atividades diárias ou mais complexas tomadas de decisão".

\subsubsection{AGILIDADE NO ATENDIMENTO}

O fluxo de documentos executado de forma aperfeiçoada e correta faz com que consequentemente se tenha melhor rapidez no atendimento, proporcionando consequentemente um menor tempo de espera dos clientes e satisfação dos mesmos no que diz respeito às opiniões sobre a loja.

Segundo Costa; Santana e Trigo (2015, p. 162)

Para obter um bom atendimento as empresas precisam investir cada vez mais no desenvolvimento dos seus recursos humanos, ou seja, para buscar a qualidade é preciso ter pessoas competentes e organizadas, que estão dispostas a oferecer um serviço que possa encantar o cliente. É fundamental que todos os colaboradores saibam

RC: 84591

Disponível em: https://www.nucleodoconhecimento.com.br/administracao/ferramenta-5w2h 
se relacionar bem com os clientes da organização, pois, o cliente deseja ser bem tratado desde a telefonista até a alta direção.

A rapidez no atendimento é fundamental para que uma empresa possa ter boas críticas dos seus clientes. É por meio dela que o índice diário de metas pode ser atingido, porém, de nada vale a agilidade no atendimento se os problemas dos clientes não forem resolvidos, se torna preciso investir na agilidade, mas visando também a solução dos problemas dos seus consumidores.

\subsection{ENDOMARKETING}

Para Bueno (2013, p. 15)

O principal objetivo do endomarketing é possuir boas relações internas na empresa, fazer com que os colaboradores tenham uma visão compartilhada sobre os negócios da empresa, que eles tenham conhecimento das metas, resultados, produtos e serviços e como está o mercado em que a empresa atua.

Também conhecido como marketing interno, o endomarketing trata-se de medidas adotadas pela organização com o intuito de proporcionar treinamento e capacitação aos seus colaboradores. O objetivo de se aplicar o endomarketing na empresa é melhorar sua imagem diante de seus funcionários.

\section{MATERIAIS E MÉTODOS}

A metodologia diz respeito a uma série de processos organizados e bem planejados com a finalidade de se obter a construção do conhecimento científico de forma satisfatória.

Conforme Libório e Terra (2015, p. 15) método científico pode ser definido com um conjunto de regras básicas empregadas em uma investigação científica com o objetivo de obter resultados, de uma forma imparcial e confiável.

RC: 84591

Disponível em: https://www.nucleodoconhecimento.com.br/administracao/ferramenta-5w2h 


\subsection{PROCEDIMENTOS METODOLÓGICOS}

Trata-se de procedimentos metodológicos o caminho escolhido para se atingir determinado fim, a forma como serão empregados cada etapa do mesmo e a maneira que irá ser expressa o seu devido resultado.

Segundo Zanella (2013, p. 19) "Método é a maneira, é a forma que o cientista escolhe para ampliar o conhecimento sobre determinado objeto, fato ou fenômeno. É uma série de procedimentos intelectuais e técnicos adotados para atingir determinado conhecimento".

\subsubsection{QUANTO À NATUREZA}

Esta pesquisa toma como base as informações extraídas por meio de entrevistas com colaboradores do nível operacional e tático da empresa do ramo de serviços de telefonia, analisando o fluxo de trabalho diário, o nível de agilidade no atendimento ao cliente e as informações documentais em cada serviço prestado e por fim propondo sua devida solução.

\subsubsection{QUANTO AOS FINS}

Face à problemática apresentada foca-se na melhoria da qualidade de atendimento e maximização das vendas, uma vez que as mesmas enfrentam constante problema na demora do atendimento decorrente da burocracia e problemas de oriundos de outras fontes não burocrática, porém referentes a mesma linha (contas atrasadas, contas cobradas endividamento, fraudes, cancelamentos de linhas de parente).

De acordo com Vergara (2016, pág. 74)," pesquisa metodológica é o estudo que se refere a instrumentos de captação ou de manipulação da realidade".

RC: 84591

Disponível em: https://www.nucleodoconhecimento.com.br/administracao/ferramenta-5w2h 


\subsubsection{QUANTO AOS MEIOS}

Objetivamos para a solução dos problemas em questão a implantação de um sistema mais intuitivo e de autoatendimento almejando que os problemas mais simples sejam resolvidos pelos próprios clientes, assim, possibilitando aos atendentes um foco maior nas vendas. Outros sim é necessária uma atualização na atividade de supervisão de vendas onde os mesmos tomam a atitude de ajudar com os problemas de clientes nos dias de maior fluxo deixando assim os atendentes mais focados na prospecção de novos clientes e venda de produtos da operadora. Aproveitando o foco na solução de problemas pela supervisão, o mesmo pode realizar também um círculo de controle de qualidade (CCQ) uma vez que o mesmo terá um maior envolvimento com a atividade que está sendo desenvolvida.

Segundo Caxito (2012, p. 125) o CCQ é conhecido como grupos de funcionários que se dedicam a controlar uma determinada área, que conforme a problemática em questão é o atendimento com foco na maximização de vendas.

Focando ainda na qualidade de atendimento dos clientes é interessante a inclusão de um profissional a fim de explicar a função de cada opção do painel interativo, oferecendo assim ao cliente a opção que melhor solucionará o seu problema. Assim como a aquisição de uma máquina que possibilita a troca de chip sem grande burocracia maximizando a agilidade no atendimento e a atividade da equipe da loja. Caxito (2012, p. 126) orienta sobre a busca de melhorias no fluxo de pessoas ou materiais a fim de reduzir o custo de movimentação projetando o arranjo físico da produção levando em consideração os fatores:

- Inclusão entre pessoal, máquinas e equipamentos

- Sequência ou fluxo de operação

- Capacidade de produção

- Flexibilização e o uso adequado do espaço

RC: 84591

Disponível em: https://www.nucleodoconhecimento.com.br/administracao/ferramenta-5w2h 
Destacando tópicos apresentados pelo autor nos possibilita vislumbrar que nosso projeto de melhoria está cumprindo com a ideia de um atendimento mais tecnológico, efetivo e principalmente de maior benéfico ao cliente.

\subsection{CARACTERIZAÇÃO DA EMPRESA}

A Loja Claro Brasil S/A do Amazonas Shopping iniciou suas atividades no ano de 2013, a mesma encontra-se localizada na Avenida Djalma Batista, № 482, Bairro: Parque 10 de novembro, CEP: 69050- 010, em Manaus-AM.

Por estar localizada em um Shopping Center, seu horário de funcionamento está de acordo com o estabelecimento comercial. A loja conta atualmente com 18 funcionários, sendo 1 para gerenciar todo o estabelecimento e 17 distribuídos na área de vendas e soluções de serviços. Seu intuito é oferecer para empresas, entidades públicas, cooperativas e associações o serviço de internet banda larga móvel e residencial de acordo com cada necessidade, bem como serviços e promoções para seus clientes, buscando a fidelização dos mesmos.

\section{RESULTADOS E DISCUSSÕES}

Os resultados e discussões trata-se da amostragem obtidas por meio de análise feita mediante o Diagnóstico organizacional e, com base nesses demonstrativos são expostos os comentários resultantes desta análise.

Mediante fundamentação nos estudos executados na etapa do Diagnóstico Organizacional, constata-se que a empresa analisada detém em suas áreas funcionais uma boa distribuição departamental da organização, como podemos observar no Gráfico 01: Medição de desempenho.

RC: 84591

Disponível em: https://www.nucleodoconhecimento.com.br/administracao/ferramenta-5w2h 
Gráfico 01: Medição de desempenho.

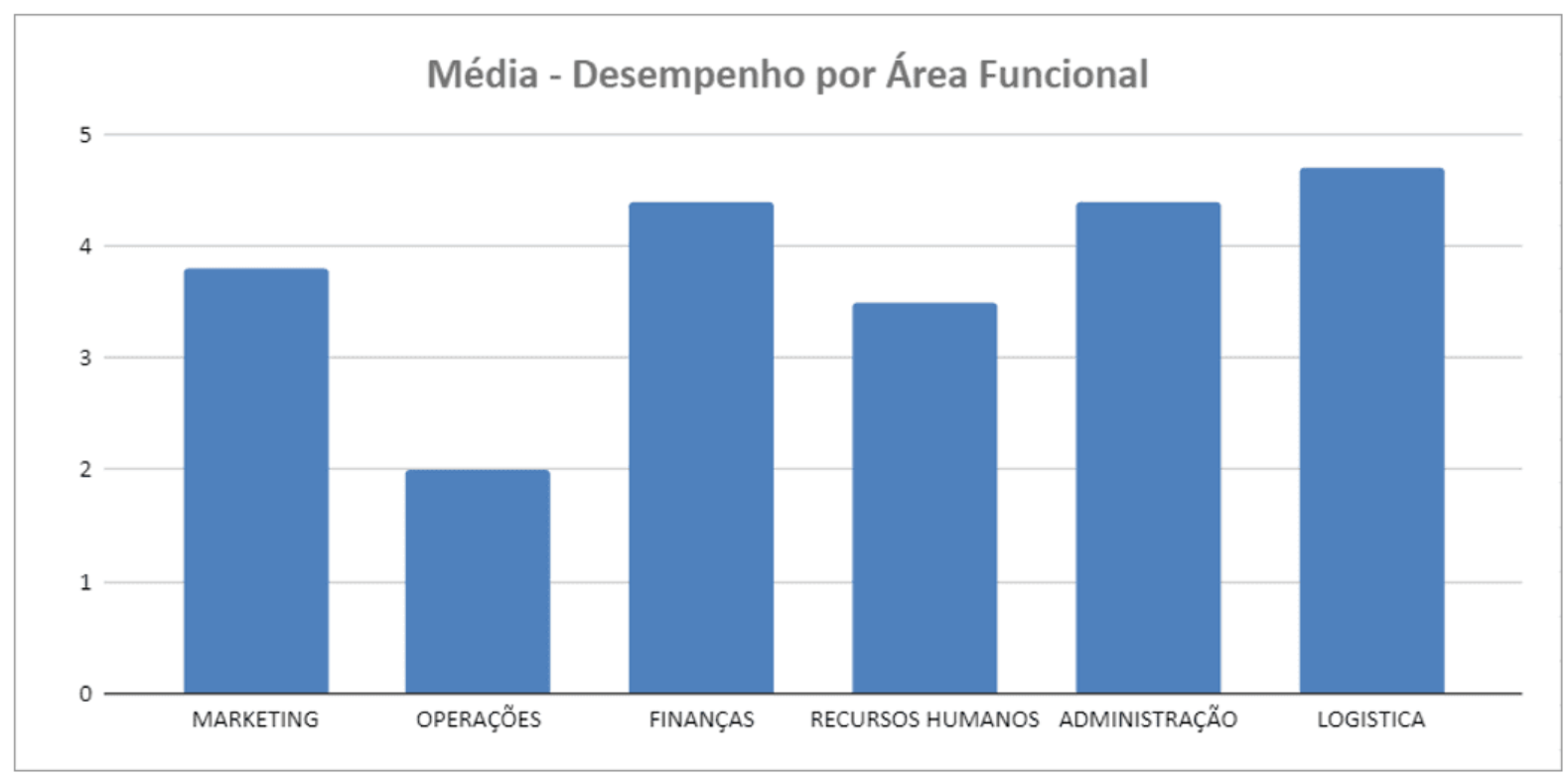

Fonte: Elaborado pelos autores com base na coleta de dados, em 2020.

Nota-se que a empresa tem a área de logística, administração e finanças como as de melhor desempenho, seguidas por marketing e recursos humanos que são áreas de desempenho médio. Por outro lado, a área de operações é considerada a mais crítica, como podemos observar.

Lopes, Rodrigues e Steiner (2013, p. 130) afirmam que "o bom desempenho de alguns agentes pode direcionar o trabalho dos demais a um conjunto promissor de soluções".

RC: 84591

Disponível em: https://www.nucleodoconhecimento.com.br/administracao/ferramenta-5w2h 
Quadro 01: Operações.

\begin{tabular}{|c|c|c|c|c|c|c|}
\hline \multicolumn{2}{|c|}{ AREA FUNCIONAL } & \multicolumn{5}{|c|}{ NIVEL OU GRAU DE AVALIAÇÃO } \\
\hline \multicolumn{2}{|r|}{ OPERAÇÕES } & Ponto & $\begin{array}{l}\text { Ponto } \\
\text { forte } 4\end{array}$ & $\begin{array}{c}\text { Ponto } \\
\text { médio } 3\end{array}$ & $\begin{array}{l}\text { Ponto } \\
\text { fraco } 2\end{array}$ & $\begin{array}{l}\text { Ponto } \\
\text { muito }\end{array}$ \\
\hline 1 & Qualidade de serviço & & & $\mathrm{x}$ & & \\
\hline 2 & Planejamento do processo de venda & & & & $x$ & \\
\hline 3 & Planejamento do arranjo físico e layout & $\mathrm{x}$ & & & & \\
\hline 4 & Administração de estoques de aparelhos e chips & & $\mathrm{x}$ & & & \\
\hline 5 & Tempo de espera de atendimento & & & & & $\mathrm{x}$ \\
\hline 6 & Processo burocrático do fechamento de venda & & & & & $\mathrm{x}$ \\
\hline 7 & Escala de pré-atendimento & & & & & $\mathrm{x}$ \\
\hline 8 & A equipe de atendimento ao cliente possui treinamento adequedo & & & $x$ & & \\
\hline 9 & Divisão de equipes para vendas e para outros atendimentos & & & & $x$ & \\
\hline 10 & A equipe sempre buscar otimizar seu tempo de atendimento & & & $x$ & & \\
\hline \multicolumn{2}{|c|}{ TOTAL ( $(\Sigma)$} & & 4 & 9 & 4 & 3 \\
\hline \multicolumn{2}{|c|}{ MÉDIA POR GRAU (POR COLUNA) } & 0 & 0,4 & 0,9 & 0,4 & 0,3 \\
\hline \multicolumn{2}{|c|}{ DESEMPENHO DA ÁREA ( $\Sigma$ ) TOTAL } & \multicolumn{5}{|c|}{2} \\
\hline
\end{tabular}

* Sendo 5 valor máximo (ponto muito forte) e 1 valor mínimo (ponto muito fraco). Fonte: Elaborado pelos autores com base na coleta de dados, em 2020.

Segundo Tadeu e Salum (2012, p. 76)

A necessidade do profundo entendimento sobre a gestão de operações refere-se à própria integração dos processos organizacionais, bem como à necessidade da sua definição, de tal forma que as organizações apresentem maior velocidade de resposta e performance em seus modelos de negócio.

De acordo com os fatores críticos expostos no Quadro 01 podemos analisar pontos essenciais na área de operações na Loja Claro do Amazonas Shopping, que são importantes para a produtividade em seus processos de vendas e agilidade em seus serviços. Desta forma a problemática da pesquisa consiste em: Como uma política de treinamento voltada ao incremento do nível de serviço pode proporcionar a redução do tempo de atendimento aos clientes?

RC: 84591

Disponível em: https://www.nucleodoconhecimento.com.br/administracao/ferramenta-5w2h 


\subsection{PLANEJAMENTO DE AÇÕES}

Processos mal planejados resultam em desperdício de tempo e desempenho. É fundamental o bom planejamento de ação para que se possa ter bons resultados. $\mathrm{O}$ planejamento de ações se dá através de uma série de etapas que contribuirão para a melhoria ou mesmo mudança em uma determinada atividade com o propósito de se atingir o melhor resultado possível atingindo, deste modo, os objetivos propostos na loja.

Quadro 02: Ações interventivas.

\begin{tabular}{|l|l|l|l|l|}
\hline Item & Ação Interventiva & Cronologia & Duração & Custo \\
\hline 1. & $\begin{array}{l}\text { Implementar programa de treinamento } \\
\text { voltado ao incremento do nível de } \\
\text { serviço }\end{array}$ & Abril/2021 & Três dias & $\mathrm{R} \$$ \\
\hline 2. & $\begin{array}{l}\text { Estruturar um cronograma de reuniões } \\
\text { diárias de comitê de crise para }\end{array}$ & Março/2021 & Dois dias & $\mathrm{R} \$$ \\
& soluções de problemas & & $1.300,00$ \\
\hline 3. & $\begin{array}{l}\text { Organizar um novo procedimento no } \\
\text { fluxo de documentos administrativos }\end{array}$ & Maio/2021 & Cinco & $\mathrm{R} \$$ \\
\hline 4. & $\begin{array}{l}\text { Esquematizar um procedimento } \\
\text { voltado à divulgação das ferramentas } \\
\text { de endomarketing }\end{array}$ & Junho/2021 & Um dia & $1.400,00$ \\
\hline Total & $\mathrm{R} \$$ & & $1.500,00$ \\
\hline
\end{tabular}

Fonte: Elaborado pelos autores, 2020.

A ideia para a solução das etapas citadas no quadro se deu por meio da ferramenta da qualidade chamada $5 \mathrm{~W} 2 \mathrm{H}$. É através de sua utilização que podemos definir 
processos de maneira mais eficaz, bem como monitorá-los de maneira simples, ágil e visual.

A qualidade jamais deve ser vista e entendida apenas sob o aspecto de "controle", mas no contexto amplo de gestão, a determinante influência da cultura e hábitos de consumo direciona a processos produtivos eficientes e a uma organização competitiva (CAMARGO, 2011, p. 19).

\subsubsection{IMPLEMENTAR PROGRAMA DE TREINAMENTO VOLTADO AO INCREMENTO DO NÍVEL DE SERVIÇO}

É fundamental a realização de uma reunião antes de tudo com o propósito de identificar os pontos fortes e fracos de cada funcionário, com o intuito de trabalhar as suas qualidades, buscando desta forma a melhoria em seus processos de vendas e serviços. Após a identificação de suas respectivas características, se aplicará o treinamento, buscando seu contínuo aprimoramento.

Quadro 03: 5w2h - Implementar programa de treinamento voltado ao incremento do nível de serviço

Implementar programa de treinamento voltado ao incremento do nível de serviço

O que? Treinamento para incremento do nível de serviço

Por quê? Para melhoria de processos no atendimento e serviços da loja

Onde? Na loja da Claro do Amazonas Shopping

Quando? Abril/2021

Quem? Departamento de Operações

Em uma reunião com os colaboradores do departamento se buscará identificar os principais fatores que causam um mal funcionamento nos

Como? serviços e, com isto, o treinamento adequado será executado

Quanto? $R \$ 2.000,00$

Fonte: Elaborado pelos autores, 2021.

RC: 84591

Disponível em: https://www.nucleodoconhecimento.com.br/administracao/ferramenta-5w2h 


\subsubsection{ESTRUTURAR UM CRONOGRAMA DE REUNIÕES DIÁRIAS DE ACOMPANHAMENTO E SOLUÇÕES DE PROBLEMAS}

A execução desta ação resultará em uma melhor sincronia nos processos de serviços, bem como na atualização dos dados documentais e do sistema, buscando sempre agilidade e melhoria contínua no atendimento, capacitando ainda mais os vendedores transformando $o$ atendimento e uma experiência boa para o cliente $e$ consequentemente levando para vida dos colaboradores mais conhecimento quanto a otimização e administração de tempo.

Sabe-se que as reuniões de equipe são comuns no contexto do trabalho em saúde, porém, o modo como são realizadas por equipes interdisciplinares poderá trazer um conteúdo de inovação, entendendo que um dos fatores que interfere nesse aspecto é a compreensão que os trabalhadores têm a respeito desse espaço (SANTOS et al., 2017, p. 607).

Quadro 04: 5w2h - Estruturar um cronograma de reuniões diárias de acompanhamento e soluções de problemas.

\section{Estruturar um cronograma de reuniões diárias de acompanhamento e soluções de problemas}

O que? Reuniões diárias para soluções de problemas

Por quê? Para manutenção e melhoria nos serviços

Onde? Na loja da Claro do Amazonas Shopping

Quando? Março/2021

Quem? Departamento de Operações

Como? As reuniões serão realizadas ao final do expediente para explorar e corrigir problemas ocorridos durante o dia.

Quanto? $\mathrm{R} \$ 1.300,00$

Fonte: Elaborado pelos autores, 2021.

RC: 84591

Disponível em: https://www.nucleodoconhecimento.com.br/administracao/ferramenta-5w2h 


\subsubsection{ORGANIZAR UM NOVO PROCEDIMENTO NO FLUXO DE DOCUMENTOS ADMINISTRATIVOS}

Mesmo com a tecnologia atual, os documentos continuam sendo bons registros de dados que tem o propósito de assegurar tanto cliente quanto a empresa.

Quadro 05: 5w2h - Organizar um novo procedimento no fluxo de documentos administrativos.

\section{Organizar um novo procedimento no fluxo de documentos administrativos}

0 que? Melhoria nos fluxos documentais administrativos

Por quê? Porque existe demora com relação aos trâmites dos documentos

Onde? Na loja da Claro do Amazonas Shopping

Quando? Maio/2021

Quem? Departamento de Operações

Como? Análise de cada etapa do processo, posterior eliminação de etapas irrelevantes e aplicação de processo mais direto e ágil.

Quanto? $\mathrm{R} \$ 1.400,00$

Fonte: Elaborado pelos autores, 2021.

É necessário conscientizar os colaboradores sobre a sequência de procedimentos documentais para que não haja divergência nos resultados dos mesmos no que diz respeito à sua entrega aos clientes. Com o fluxo documental padronizado a eficiência e a agilidade no atendimento terão um reflexo significativamente positivo, mas para isso, se faz necessário a análise e bom planejamento.

\subsubsection{ESQUEMATIZAR UM PROCEDIMENTO VOLTADO À DIVULGAÇÃO DAS FERRAMENTAS DE ENDOMARKETING}

Manter os colaboradores motivados e capacitados garante a boa imagem da empresa não só em relação aos clientes como também aos próprios funcionários. Uma RC: 84591

Disponível em: https://www.nucleodoconhecimento.com.br/administracao/ferramenta-5w2h 
empresa que investe no bem-estar e visa sempre cuidar de seus colaboradores cria laços que vão além do trabalho.

Quadro 07: 5w2h - Esquematizar um procedimento voltado à divulgação das ferramentas de endomarketing:

\section{Esquematizar um procedimento voltado à divulgação das ferramentas de endomarketing}

\begin{tabular}{|l|l|}
\hline O que? & Procedimento para divulgação das ferramentas de endomarketing \\
\hline Por quê? & Para manter os colaboradores motivados \\
\hline Onde? & Na loja da Claro do Amazonas Shopping \\
\hline Quando? & Junho/2021 \\
\hline Quem? & Departamento de Operações \\
\hline Como? & $\begin{array}{l}\text { Analisar as possíveis causas que deixam os funcionários desmotivados, } \\
\text { executar as ferramentas de endomarketing para garantir a mudança e } \\
\end{array}$ \\
\hline
\end{tabular}

Quanto? R\$1.500,00

Fonte: Elaborado pelos autores, 2021.

\subsection{FLUXOGRAMA DA MELHORIA PROPOSTA:}

Tomando como base a análise dos procedimentos no atendimento ao cliente presente na área de operações, foi criado e proposto um novo padrão de fluxograma no processo com o intuito de agilizar o tempo de atendimento intensificando assim a triagem que ao invés de oferecer ao cliente um conglomerado de serviços passará a filtrar problemas a serem resolvidos de oportunidades de venda, o problema identificado é enviado a supervisão onde o mesmo gera um protocolo e finaliza o atendimento, já a oportunidade de venda é encaminhada ao vendedor otimizando o tempo. No fluxograma anterior o mesmo levaria mais tempo identificando o problema e gerando protocolo do que vendendo o que consequentemente necessitavam de mais tempo no atendimento.

$\mathrm{RC}: 84591$

Disponível em: https://www.nucleodoconhecimento.com.br/administracao/ferramenta-5w2h 
De acordo com Galvão $(2017$, p. 12)

O fluxograma é um tipo de diagrama. É uma representação gráfica das etapas de um determinado processo na qual, além da sequência de atividades, são apresentados os serviços prestados, as entradas e saídas de documentos, as decisões tomadas e os entes envolvidos.

Imagem 01:Fluxograma da melhoria proposta.

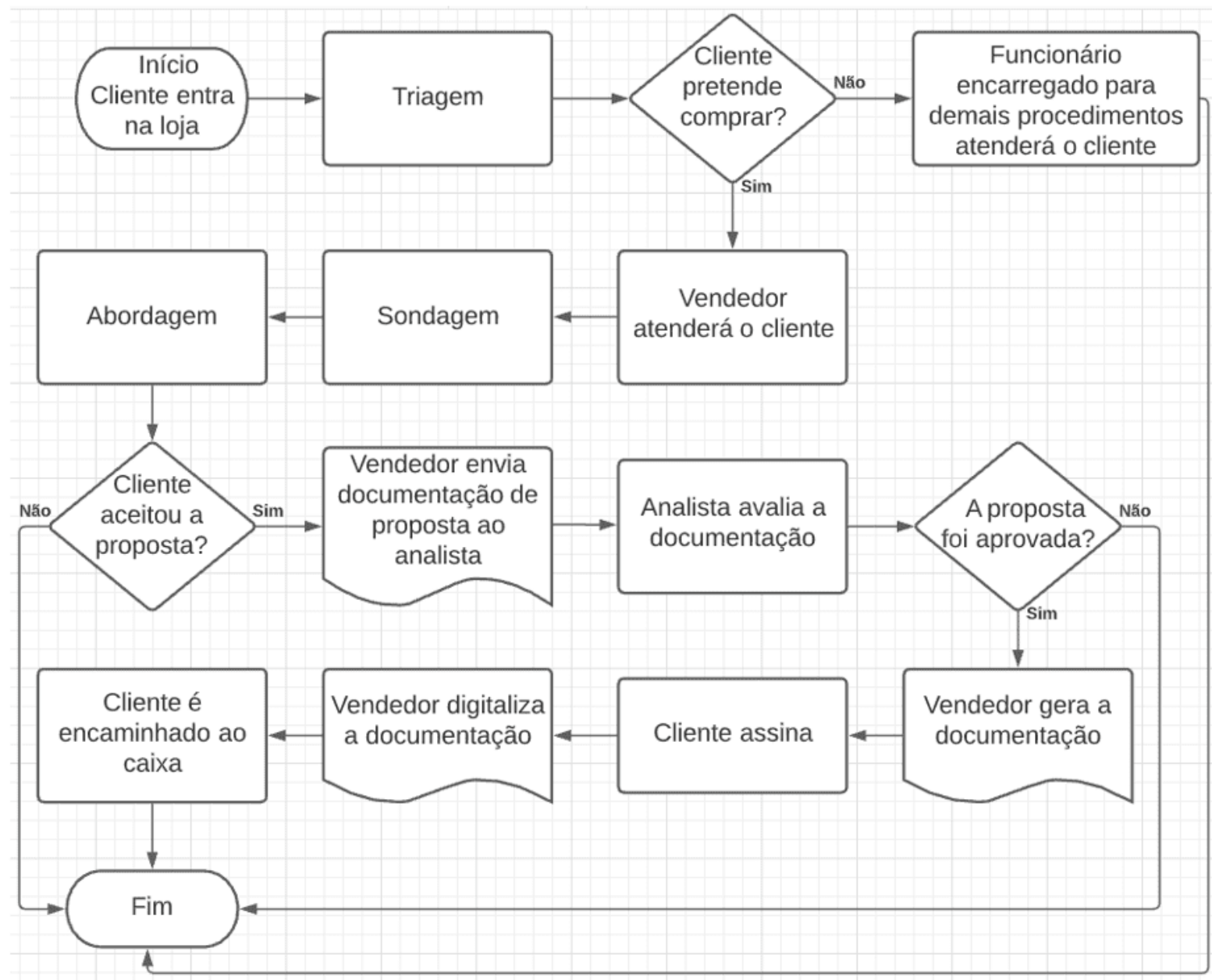

Fonte: Elaborado pelos autores, 2021.

\section{CONSIDERAÇÕES FINAIS}

A proposta para a realização desse estudo deu-se a partir de uma pesquisa de campo realizada na loja Claro Amazonas shopping que foi encontrada uma falha nos

RC: 84591

Disponível em: https://www.nucleodoconhecimento.com.br/administracao/ferramenta-5w2h 
processos que ocasionaram demora no atendimento e consequentemente desistência de pessoas que aguardavam atendimento com o objetivo de fazer aquisições de produtos e serviços. Sendo assim foi feita a implementação da ferramenta da qualidade $5 \mathrm{~W} 2 \mathrm{H}$ com o propósito de executar um plano de ação a fim de maximizar as vendas e trazer melhoria aos processos.

Foi desenvolvido um plano de ação para melhorar o atendimento ao cliente através de reuniões e treinamentos junto a um novo modelo de fluxograma para aperfeiçoar os processos e garantir mais agilidade.

A agilidade no processo se torna um diferencial competitivo em relação a captação de mais clientes, quando a loja começa atender mais rápido e ter um filtro melhor consequentemente a loja começa atender mais e vender mais. A pesquisa atingiu o objetivo de analisar a causa da demora no atendimento, que estava relacionada ao filtro no atendimento e ao excesso de burocracia e papelório da loja e pode aplicar um sistema de treinamento e capacitação de funcionários.

A hipótese foi confirmada a partir da implementação da ferramenta da qualidade $5 \mathrm{~W} 2 \mathrm{H}$ e das demais medidas tomadas em relação ao problema encontrado. A hipótese era de que haveria uma melhoria dos processos funcionais da loja a partir da conscientização dos funcionários e da reformulação dos processos na forma de atendimento.

A metodologia utilizada para obter informações foram extraídas por meio de entrevistas com colaboradores do nível operacional e tático da empresa do ramo de serviços de telefonia, analisando o fluxo de trabalho diário, o nível de agilidade no atendimento ao cliente e as informações documentais em cada serviço prestado e por fim propondo sua devida solução. Sendo assim foi constatado que as medidas tomadas trazem mais efetividade aos processos sempre em busca da melhoria contínua.

RC: 84591

Disponível em: https://www.nucleodoconhecimento.com.br/administracao/ferramenta-5w2h 


\section{REFERÊNCIAS BIBLIOGRÁFICAS}

BUENO, Bárbara Mariane Aparecida. Endomarketing: Uma ferramenta estratégica de gestão. FEMMA - ASSIS, 2013;

CAMARGO, Wellington. Controle de Qualidade Total. Curitiba-PR: Editora E Tec Brasil, 2011;

CAXITO, Fabiano de Andrade. Produção: fundamentos e processos. 1. Ed., rev. Curitiba: IESDE Brasil, 2012;

COSTA, Ariane de Souza Carvalho; SANTANA, Lidia Chagas de; TRIGO, Antônio Carrera. Qualidade do atendimento ao cliente: um grande diferencial competitivo para as organizações. Revista de Iniciação Científica-RIC Cairu, v. 2, n. 2, p. 155-172, 2015.

Disponível

em:

https://www.cairu.br/riccairu/pdf/artigos/2/10_QUALIDADE_ATEND_CLIENTE.pdf. Acesso em: 25/03/2021;

COVEY, Stephen Richards. Os 7 hábitos das pessoas altamente eficazes. 74. ed. Rio de Janeiro: Best Seller 2019;

GALVÃO, Gardênia de Oliveira. Manual de Fluxogramas. Natal: IFRN, 2017;

LIBÓRIO, Daisy; TERRA, Lucimara. Metodologia Científica. São Paulo: Rede Internacional de Universidades Laureate, 2015;

LOPES, Heitor Silvério; RODRIGUES, Luiz Carlos de Abreu; STEINER, Maria Teresinha Arns. Meta-Heurísticas em Pesquisa Operacional. Curitiba: Omnipax, 2013;

MARTINS, Jarbas Rocha; BONFIM, Willane Balbino. Coletânea Nacional Sobre Engenharia de Produção 3: Gestão da Produção. Curitiba: Atena, 2017; 
MEDEIROS, Janine Fleith de; CRUZ, Cassiana Maris Lima; ANTONI, Verner Luis. Gestão de Marketing: Conceitos, processos e aplicações. Passo Fundo: UPF Editora, 2013;

OSHIRO, Angela dos Santos. Administração de cargos e salários. 1. Ed. Vila Velha: ESAB, 2011;

SANTOS, Elitiele Ortiz dos, et al. Reunião de equipe: proposta de organização do processo de trabalho. Revista de Pesquisa Cuidado é Fundamental Online. Rio de Janeiro, RJ, v. 9, n. 3, p. 606-613, 2017. DOI: http://dx.doi.org/10.9789/21755361.2017. v9i3.606-613.

Disponível

em: https://www.redalyc.org/pdf/5057/505754116001.pdf. Acesso em: 29/03/2021;

SOUZA, Camila Gracielli Ferreira; GONÇALVES, Renata Ruiz. TREINAMENTO E DESENVOLVIMENTO DE PESSOAS - FATOR DE SUCESSO EM VENDAS. Semana Acadêmica. Fortaleza, ano 2013, №. 000025, 2013. Disponível em: https://semanaacademica.com.br/artigo/treinamento-e-desenvolvimento-de-pessoasfator-de-sucesso-em-vendas. Acesso em: 23/03/2021;

TADEU, Hugo Ferreira Braga; SALUM, Fabian Ariel. Estratégia, operações e inovação: Paradoxo do Crescimento. São Paulo: Cengage Learning, 2012.

TEIXEIRA, Livia Marangon Duffles; AGANETTE, Elisângela Cristina. Os processos de negócio, a gestão de documentos e os fluxos documentais: algumas perspectivas e relações. RDBCl: Revista Digital de Biblioteconomia e Ciência da Informação. Campinas, SP, v. 16, n. 3, p. 427-439, 2018. DOI: 10.20396/rdbci.v16i3.8651321. Disponível

em: https://periodicos.sbu.unicamp.br/ojs/index.php/rdbci/article/view/8651321. Acesso em: 25/03/2021;

VERGARA, Sylvia Constant. Projetos e Relatórios de Pesquisa em Administração. 16. Ed. São Paulo: Editora Atlas S.A, 2016;

RC: 84591

Disponível em: https://www.nucleodoconhecimento.com.br/administracao/ferramenta-5w2h 
ZANELLA, Liane Carly Hermes. Metodologia de Pesquisa. 2. Ed., reimpr. Florianópolis: Departamento de Ciências da Administração/UFSC, 2013.

Enviado: Abril, 2021.

Aprovado: Maio, 2021. 